\title{
Toward Evidence-Based Genetic Research on Lifelong Premature Ejaculation: A Critical Evaluation of Methodology
}

\author{
Marcel D. Waldinger ${ }^{1,2}$ \\ ${ }^{1}$ Department of Psychiatry and Neurosexology, HagaHospital, The Hague, ${ }^{2}$ Department of Pharmacology, Utrecht Institute for \\ Pharmaceutical Sciences, Faculty of BetaSciences, Utrecht University, Utrecht, The Netherlands
}

Recently, four premature ejaculation (PE) subtypes have been distinguished on the basis of the duration of the intravaginal ejaculation latency time (IELT). These four PE subtypes have different etiologies and pathogeneses. Genetic research on PE should consider the existence of these PE subtypes and the accurate measurement of the IELT with a stopwatch. Currently, three methods of genetic research on PE have been used. They differ in the investigated population, tool of measurement, study design, and variables of PE. From animal and human research, it is derived that the central serotonergic system "modulates" ejaculation, whereas the ejaculation (reflex) itself is probably not under direct influence of the serotonergic system, but rather under the influence of other neurotransmitter systems in the spinal cord. For genetic research on PE, it is important to take into account that the (serotonergic) modulation of the IELT is variable among men and may even be absent. This means that serotonergic genetic polymorphisms may only be found in men with $\mathrm{PE}$ who respond with an ejaculation delay on treatment with a selective serotonin reuptake inhibitor.

\section{Key Words: Ejaculation, Genetic research, Serotonin}

This is an Open Access article distributed under the terms of the Creative Commons Attribution Non-Commercial License (http://creativecommons.org/licenses/by-nc/3.0) which permits unrestricted non-commercial use, distribution, and reproduction in any medium, provided the original work is properly cited.

\author{
Article History: \\ received 28 November, 2010 \\ accepted 16 December, 2010
}

\section{INTRODUCTION}

In 1998 , Waldinger et al postulated that there is a continuum of the intravaginal ejaculation latency time (IELT) in the general male population and that this variability in the IELT is influenced by neurobiological and genetic mechanisms [1]. In addition, it was postulated that the persistently short IELTs in men with lifelong premature ejaculation (PE) are associated with diminished serotonin (5-hydroxytryptamine, or 5-HT) neurotransmission, a hyperfunction of 5- $\mathrm{HT}_{1 \mathrm{~A}}$ receptors, and/or a hypofunction of 5$\mathrm{HT}_{2 \mathrm{C}}$ receptors [1]. From the strong ejaculation-delaying effects of selective serotonin reuptake inhibitors (SSRIs) and particularly that of paroxetine [2], it may be derived that serotonin and 5-HT receptors play an important role in the ejaculation process, as was already demonstrated in rodents in the 1980s [3]. However, for about a decade, the details of the neurobiological hypothesis of Waldinger et al could not be confirmed in humans owing to the absence of specific $5-\mathrm{HT}_{1 \mathrm{~A}}$ and $5-\mathrm{HT}_{2 \mathrm{C}}$ ligands that were safe for human use. However, recent genetic research on 5-HT gene polymorphisms and the IELT has provided evidence in support of the view that the persistently short IELTs in men with lifelong PE are associated with decreased 5-HT neurotransmission [4]. The idea that PE may have genetic roots was suggested for the first time indirectly in 1943, when Schapiro noted that family members of men with PE also suffered from PE [5]. This remarkable clinical observation was never quoted in sexological literature until 1998 when Waldinger et al published a study in which it was shown that in first-degree male relatives of men with lifelong PE, defined in terms of an IELT of less than $1 \mathrm{mi}-$ nute, a high percentage of men (91\%) also suffered from lifelong PE with an IELT of less than 1 minute [6]. However, because only $14(6 \%)$ of 237 men were willing to ask first-degree male relatives about their ejaculation time, this study can only be regarded as an indication that the observation of Schapiro has some validity. At the same time, the study 
demonstrated the immense taboo that exists among PE sufferers to openly talk about their PE. Because this taboo still exists today, it may be concluded that family studies on PE are also today practically impossible to perform.

Fortunately, due to new developments in laboratory techniques of the past decade, DNA research has become easier to perform in many laboratory settings nowadays. After the first publication of a DNA study in Dutch men with lifelong PE by Janssen et al [4], a small number of other genetic studies on PE in different countries, in different cohorts of men, and with different methodologies have been published. However, many clinicians, particularly those who have not been educated with current knowledge of genetics, have difficulties in understanding the details of genetic research articles and the often complex associated statistics. The aim of the current article is to clarify and critically review the current methodologies that have been used in genetic research on lifelong PE in the context of recent developments in diagnosis and classification.

\section{COMPLAINT VERSUS DISORDER}

In 2006, Waldinger et al emphasized the need to distinguish PE as a "complaint" versus PE as a "disorder" $[7,8]$. This distinction has important consequences for both epidemiologic research on PE and for the debate on definition and classification. For example, most epidemiologic studies have reported PE to be the most prevalent male sexual "disorder" $[9,10]$. However, considering the questions that have been asked in these surveys, it appears that these surveys only investigated the prevalence of males who have a "complaint" of PE. Therefore, it has to be concluded that $\mathrm{PE}$ is the most prevalent male sexual "complaint" affecting some $20 \%$ to $30 \%$ of men $[7,8]$. Until recently, the prevalence of PE as a sexual "disorder" has not been investigated in the general male population. However, the study of
Serefoglu et al showed that in $20 \%$ of men with "complaint"s of $\mathrm{PE}$, the prevalence of the sexual "disorder" of lifelong PE is rather low in the general male population [11].

\section{FOUR PREMATURE EJACULATION SUBTYPES}

The very high percentage of $20 \%$ to $30 \%$ of men in the general male population who suffer from complaints of $\mathrm{PE}[8,9$, 11] contrasts with the rather low percentage of men who visit outpatient clinics for medical treatment of PE [12]. The argument to explain this low percentage by the everexisting taboo to talk about PE probably only partially explains this remarkable difference. An additional explanation has been put forward by Waldinger et al, who stated that the prevalence of $20 \%$ to $30 \%$ does not represent the number of men who suffer from lifelong or acquired PE [13-16]. Waldinger et al reported that in contrast with the high percentage of men who have complaints of $\mathrm{PE}$ without having a short ejaculation time of less than one minute, the prevalence of the disorders of lifelong and acquired $\mathrm{PE}$ with IELTs of less than one minute is rather low (2.5\%) in the general male population [13-18]. Presuming that the persistent, very short IELTs of less than one minute are a major disturbing factor for a man's self-esteem, sexual selfconfidence, and feelings of masculinity, the rather low percentage of men who actively seek medical treatment most probably represents the rather low percentage of men with lifelong and acquired PE in the general male population. In 2006, Waldinger et al suggested that apart from the two well-known subtypes of PE (e.g., lifelong PE and acquired PE), there are also two other PE subtypes: natural variable PE and premature-like ejaculatory dysfunction (Table 1) $[7,13]$. In natural variable PE, men only occasionally suffer from early ejaculations. In premature-like ejaculatory dysfunction, men experience or complain of PE while actually having a normal or even a long IELT duration of, for exam-

TABLE 1. New preliminary classification and characteristics of four premature ejaculation subtypes on the basis of their IELT durations [14-16]

\begin{tabular}{|c|c|c|c|}
\hline $\begin{array}{l}\text { Lifelong premature } \\
\text { ejaculation }\end{array}$ & $\begin{array}{c}\text { Acquired premature } \\
\text { ejaculation }\end{array}$ & $\begin{array}{c}\text { Natural variable premature } \\
\text { ejaculation }\end{array}$ & $\begin{array}{l}\text { Premature-like } \\
\text { ejaculatory dysfunction }\end{array}$ \\
\hline $\begin{array}{l}\text { Ejaculation occurs too early, at } \\
\text { (nearly) every intercourse }\end{array}$ & $\begin{array}{l}\text { Early ejaculation occurs at } \\
\text { some point in a man's life }\end{array}$ & $\begin{array}{l}\text { Early ejaculations are incon- } \\
\text { sistent and occur irregularly }\end{array}$ & $\begin{array}{l}\text { Subjective self-perception of } \\
\text { (in)consistent rapid ejacu- } \\
\text { lations }\end{array}$ \\
\hline With (nearly) every woman & $\begin{array}{l}\text { The man had normal ejacu- } \\
\text { lation experiences before }\end{array}$ & $\begin{array}{l}\text { The ability to delay ejaculation } \\
\text { may be diminished or lacking }\end{array}$ & $\begin{array}{l}\text { The ability to delay ejaculation } \\
\text { may be diminished or lacking }\end{array}$ \\
\hline $\begin{array}{l}\text { From about the first sexual en- } \\
\text { counters onwards }\end{array}$ & $\begin{array}{l}\text { The onset is (usually) at later } \\
\text { age }\end{array}$ & $\begin{array}{l}\text { From about the first sexual en- } \\
\text { counters or onset at later age }\end{array}$ & $\begin{array}{l}\text { From about the first sexual en- } \\
\text { counters or onset at later age }\end{array}$ \\
\hline $\begin{array}{l}\text { In } 80 \% \text { within } 1 \text { minute (mostly } \\
\text { within } 30 \mathrm{~s} \text { ) } \\
\text { In } 20 \% \text { between } 1 \text { and } 2 \text { mi- } \\
\text { nutes }\end{array}$ & $\begin{array}{l}\text { Ejaculation occurs within 1-2 } \\
\text { minutes }\end{array}$ & $\begin{array}{l}\text { Ejaculation time may be short } \\
\text { or normal }\end{array}$ & $\begin{array}{l}\text { Ejaculation time is in the nor- } \\
\text { mal range or may even be of } \\
\text { longer duration }\end{array}$ \\
\hline $\begin{array}{l}\text { Ejaculation remains rapid } \\
\text { throughout the lifetime of the } \\
\text { subject }\end{array}$ & $\begin{array}{l}\text { Rapid ejaculation is result of } \\
\text { urological, thyroid, or psycho- } \\
\text { logical problems }\end{array}$ & $\begin{array}{l}\text { This is part of the normal varia- } \\
\text { bility of ejaculatory function- } \\
\text { ing }\end{array}$ & $\begin{array}{l}\text { Rapid ejaculation is a subjective } \\
\text { experience independent of ac- } \\
\text { tual ejaculation time, which is } \\
\text { in the normal range }\end{array}$ \\
\hline
\end{tabular}


ple, 5 to 20 minutes [14-16]. The 4 PE subtypes are distinguished on the basis of the IELT duration. In the 1990s, Waldinger et al postulated that lifelong $\mathrm{PE}$ is mainly influenced by neurobiological and genetic factors and showed that it is characterized by an IELT of less than 1 minute, usually within about $30 \mathrm{~s}$ [19]. Acquired PE is caused by either medical or psychological causes and is also characterized by a short IELT, most probably between 1 and 2 minutes [14]. On the other hand, natural variable PE is considered a normal variation of ejaculatory performance and should not be regarded as an ejaculatory disorder. It has been presumed that the IELT in this subtype is in the normal range. Premature-like ejaculatory dysfunction is considered to be caused by psychological, cultural, or interrelationship factors and is not considered to be caused by neurobiological or genetic factors [14-16]. Its IELTs are in the normal range or even of longer duration. For a better understanding, premature-like ejaculatory dysfunction may also be denominated as subjective premature ejaculation. Importantly, Waldinger emphasized that the four PE subtypes are characterized by different etiologies and have a different pathogenesis and therefore should be separately defined [14-16]. He assumed that the prevalence of lifelong and acquired $\mathrm{PE}$ is probably low in the general male population but high in outpatient clinics of urology [14-16], whereas oppositely he also presumed that the prevalence of natural variable $\mathrm{PE}$ and premature-like ejaculatory dysfunction or subjective $\mathrm{PE}$ is high in the general male population but rather low in outpatient clinics of urology [14-16]. In addition, Waldinger argued that the sum of the prevalences of these four PE subtypes constitutes the $20 \%$ to $30 \%$ prevalence of $\mathrm{PE}$ as has often been found in epidemiologic studies [14-16].

Interestingly, two studies by Serefoglu et al investigating the prevalence of the $4 \mathrm{PE}$ subtypes in Turkey confirmed the existence of the $4 \mathrm{PE}$ subtypes in both an outpatient clinic of urology and in the general male population (Table 2) [11,20]. Moreover, the self-reported IELT values in their study indeed showed a continuum, with the shortest IELTs in lifelong PE and the longest IELTs in subjective
PE. Also, the prevalence rates of the $4 \mathrm{PE}$ subtypes were in accordance with the hypothesis of Waldinger. The prevalence of lifelong PE was low in the general male population but very high in the outpatient clinic of urology, giving support to the validity of this new PE classification. However, more studies using the methodology of Serofoglu et al in other countries are warranted to further investigate the validity of this classification $[11,20]$.

\section{DEFINITION OF PREMATURE EJACULATION}

Until 1980, PE was not officially defined. In the mid of the last century, when many PE sufferers were treated by psychoanalysis, psychoanalysts considered a man to have PE when he ejaculated within about 1 minute [13]. However, Masters and Johnson, two representatives of behaviorism, fiercely rejected this definition in terms of ejaculation time and considered a man to suffer from PE when he was not able to control his ejaculation until the moment that he gave pleasure to his partner [21]. Their opinion influenced the first official definition of PE in the DSM-III, in which $\mathrm{PE}$ was defined solely in terms of voluntary control [22]. However, in the DSM-III-R, DSM-IV, and DSM-IV-TR versions, control has been deleted and replaced by the criterion of a short ejaculation time, without specification of a cutoff point of this "short" ejaculation time [22]. During the past decade in particular, the $D S M-I V-T R$ definition has been criticized for its vagueness [22,23], although some clinicians have also stated that the DSM-IV-TR definition of $\mathrm{PE}$ is adequate and does not require revision [24]. The debate on this definition came to an end when the International Society for Sexual Medicine (ISSM) organized a meeting of experts in the field to derive an evidence-based definition of PE [25].

\section{DEFINITION OF LIFELONG PREMATURE EJACULATION}

During this meeting in Amsterdam, the ISSM decided that there were sufficient data to define a new definition of life-

TABLE 2. Prevalences and self-reported mean and median IELT durations of the four PE subtypes in a turkish outpatient clinic of urology and in the general turkish male population $[11,20]$

\begin{tabular}{|c|c|c|c|c|}
\hline $\begin{array}{c}\text { Premature ejaculation } \\
\text { subtype }\end{array}$ & $\begin{array}{l}\text { Prevalence of PE in } \\
\text { outpatient clinic } \\
\text { n=261 males }\end{array}$ & $\begin{array}{l}\text { Self-reported mean } \\
\text { IELT (range) }\end{array}$ & $\begin{array}{l}\text { Prevalence in general Turkish } \\
\text { male population }(\mathrm{n}=2,593) \text {. } \\
\text { Males with } \mathrm{PE}(\mathrm{n}=512 ; 20 \%)\end{array}$ & $\begin{array}{l}\text { Self-reported } \\
\text { median IELT }\end{array}$ \\
\hline $\begin{array}{l}\text { Lifelong premature } \\
\text { ejaculation }\end{array}$ & $62.5 \%$ & $\begin{array}{l}20.47 \pm 28.90 \mathrm{~s} \\
(2 \mathrm{~s}-2 \mathrm{~min})\end{array}$ & $2.3 \%$ & $<1 \min$ \\
\hline $\begin{array}{l}\text { Acquired premature } \\
\text { ejaculation }\end{array}$ & $16.1 \%$ & $\begin{array}{l}57.91 \pm 38.72 \mathrm{~s} \\
(1.5-3 \mathrm{~min})\end{array}$ & $3.9 \%$ & $1-2 \min$ \\
\hline $\begin{array}{l}\text { Natural variable premature } \\
\text { ejaculation }\end{array}$ & $14.5 \%$ & $\begin{array}{l}144.17 \pm 22.47 \mathrm{~s} \\
\quad(2-3 \mathrm{~min})\end{array}$ & $8.5 \%$ & $2-3 \min$ \\
\hline $\begin{array}{l}\text { Premature-like ejaculatory } \\
\text { dysfunction }\end{array}$ & $6.9 \%$ & $\begin{array}{l}286.67-69.96 \mathrm{~s} \\
\quad(3-7 \mathrm{~min})\end{array}$ & $5.1 \%$ & $>3 \min$ \\
\hline
\end{tabular}

IELT: intravaginal ejaculation latency time 
long PE but still insufficient data for a new definition of acquired PE [25]. The ISSM defined lifelong PE as an ejaculation that occurs within about 1 minute after penetration in the majority of sexual encounters, with an inability to delay ejaculation and with associated negative personal consequences such as bother and avoidance of sexual activity [25]. Recently, the ISSM also organized a similar meeting in order to derive an evidence-based guideline for the treatment of PE [26]. With both an evidence-based definition of lifelong PE and an evidence-based guideline for the treatment of PE, the ISSM has made an enormous, historical contribution to the research and treatment of $\mathrm{PE}$.

\section{CENTRAL SEROTONERGIC MODULATION OF THE IELT}

It has become clear from both human and animal studies that serotonin (5-hydroxytryptamine, or 5-HT) plays a very important role in sexual and particularly ejaculatory activity [27-31]. Animal studies, mainly performed in laboratory rodents, have shown that various brain areas are specifically involved in ejaculatory behavior [32]. Overall, these brain areas are a complex interconnected network that regulates ejaculation. There is also a very important spinal ejaculation generator located lateral to the central canal in lamina $\mathrm{X}$ and in the medial portion of lamina VII of L3 and L4 of the lumbar spinal cord. These lumbar spinothalamic (LSt) neurons project to the medial parvocellular subparafascicular nucleus of the posterior thalamus (SPFp) and are specifically activated during ejaculation but not with other components of male rat sexual behavior [33]. Lesions of these neurons cause dramatic disruptions in ejaculatory behavior [33]. Serotonergic fibers have been found in all spinal cord areas containing sensory axons and motor neurons involved in ejaculation. They are present in the dorsal and ventral horns, dorsal commissural grey and thoracolumbar intermediolateral cell column (IML), and sacral parasympathetic nucleus (SPN) of the lumbosacral spinal cord [34]. In addition, serotonergic postsynaptic receptors have been found in the area where LSt cells are located [35]. This suggests a role of serotonin in ejaculation via these possible connections in the spinal cord. However, these serotonergic connections are also found in supraspinal areas. In the nucleus paragigantocellularis (nPGI), an area in the ventrolateral medulla of the brainstem, serotonergic neurons are found to innervate the bulbospongiosus muscles involved in the inhibition of ejaculation [35]. The medial preoptic area (MPOA) might lower the ejaculatory threshold by removing the tonic serotonergic inhibition exerted by the nPGI [36]. Another serotonergic innervation exists in the anterior lateral hypothalamic area (LHA). Lesions of the LHA in male rats strongly affect the occurrence of ejaculations, showing the excitatory role of this brain region in the regulation of ejaculation [37]. This effect is caused by serotonin, because it is released in the LHA at the time of ejaculation [38], and injections of SSRIs into the LHA were shown to increase ejaculation latencies
[38].

The ejaculatory reflex is complex and involves multiple afferent and efferent systems. The afferent stimuli may involve sensory, visceral, proprioceptive, and somatic inputs. It is possible that LSt cells receive stimuli related to the onset of ejaculation and, in turn, trigger the ejaculation reflex. The efferent site of the reflex involves the complex control of sympathetic and parasympathetic systems [33]. Briefly, ejaculation is a spinal reflex controlled by the spinal ejaculation generator that is "modulated" by sensory input from the pelvis and descending input from inhibitory and excitatory centers in the brainstem and the hypothalamus. Allard et al suggested that these supraspinal centers are controlled by cortico-limbic centers, which are responsible for switching on a state of sexual excitement [39]. During sexual intercourse, the cortico-limbic centers inhibit and activate the inhibitory and excitatory centers respectively, shifting the supraspinal tone to the spinal ejaculation generator from overall inhibitory to excitatory.

All together, the data derived from animal research suggest a major role of the central serotonergic system in modulating the spinal ejaculatory reflex. This serotonergic modulation of ejaculation may result in a faster or more delayed ejaculation, whereas the ejaculation itself is probably not under direct influence of the serotonergic system but rather under the influence of other neurotransmitter systems in the spinal cord [33]. This is an important consequence of this central modulation of ejaculation that has hardly been discussed in the literature but may be pivotal for genetic research on PE. For example, it may be assumed that the modulation of ejaculation among men is variable; it can be strong, moderate, weak, or even absent. In the last case, the serotonergic system in the brainstem is unable to modulate the ejaculation reflex in the lower spinal cord. In that case, a male is not able to or hardly able to change the duration of his ejaculation time. Even by using SSRIs, this subject may still not be able to change the duration of his ejaculation time. Although never systematically investigated, it is clinically well known that a subgroup of men with lifelong $\mathrm{PE}$ do not respond with ejaculation delay to any SSRI treatment. I therefore suggest that in these men, the serotonergic system is unable to modulate the ejaculation reflex.

The view that serotonin modulates ejaculation may have important implications for genetic research, because it may imply that in a certain cohort of men, an unknown number have no or hardly any ability to modulate ejaculation irrespective of the presence of functional serotonergic polymorphisms. Consequently, irrespective of the presence of these polymorphisms, these men will not show any change in IELT duration when modulation of the IELT is not $100 \%$ associated with such serotonergic polymorphisms.

This phenomenon may mask positive outcome data, particularly when the size of the cohort is small. In order to avoid this phenomenon, it may be argued that the odds of finding a positive association between serotonergic polymorphisms and the duration of the IELT is enhanced when 
genetic research is performed in men who develop an ejaculation delay in response to daily SSRI, e.g., paroxetine, treatment.

\section{GENETICS OF IELT, LIFELONG PE, AND PE}

It is important to distinguish (i) the genetics of the ejaculation time (e.g., the IELT), (ii) the genetics of lifelong PE, and (iii) the genetics of PE.

\section{Genetics of the IELT}

The aim of genetic research on the ejaculation time (e.g., IELT) is to investigate the genetic factors that influence or "modulate" the duration of the ejaculation time (e.g., the IELT).

\section{Genetics of lifelong PE}

The aim of genetic research on lifelong $\mathrm{PE}$ is to investigate the genetic factors that influence or are involved in the various parameters of lifelong PE.

\section{Genetics of PE}

The aim of genetic research on PE is to investigate the genetic factors that influence or are involved in men who complain of PE and who have both normal and very short ejaculation times.

\section{GENETICS AND THE FOUR PE SUBTYPES}

It should be emphasized that according to Waldinger et al, only a very small percentage of men who "complain" of PE have "genetically" based PE [14-16]. This is explained by the following arguments.

(i) Of the four PE subtypes, it has been argued that only lifelong PE is mainly influenced by genetic and neurobiological factors, because the IELT in these men persistently occurs within 1 minute independent of internal or environmental circumstances. According to this view, the genetics of lifelong PE pertains only to the neurobiological mechanisms that determine the "modulation" of the persistently very short IELTs. In the case of homosexual individuals with lifelong PE, the modulation of ejaculation is better reflected by the duration of the MELT, OELT, or AELT [40].

(ii) The prevalence of men with an IELT of less than $1 \mathrm{mi}-$ nute, irrespective of a complaint of $\mathrm{PE}$, in the general male population is about $2.5 \%[17,18]$.

(iii) The prevalence of men with an IELT of less than 1 minute and with a complaint of $\mathrm{PE}$ in the general male population is about $2.5 \%$ as well [11].

According to Waldinger et al, the duration of the ejaculation time (e.g., the IELT) is influenced by both genetic and nongenetic factors [14-16]. However, it is postulated that the genetic influences on the IELT become most manifest in men who persistently ejaculate within 1 minute, e.g., in men with lifelong PE. In contrast, with increasing genetic and neurobiological ability to delay ejaculation time, it is argued that nongenetic factors increasingly influence the
IELT duration.

The aforementioned view is the basis for the hypothesis of Janssen et al [4] that the persistently short IELTs in men with lifelong $\mathrm{PE}$ are caused by (the sum of) various genetic polymorphisms or other genetic factors that facilitate ejaculation. According to the same view, it is assumed that the genetic profile of genetic polymorphisms in men with lifelong $\mathrm{PE}$ is different from the genetic profile of genetic polymorphisms in men with natural variable $\mathrm{PE}$ or subjective $P E$, because the IELT duration in these men is not restricted to less than 1 minute.

\section{THREE DIFFERENT METHODS OF GENETIC RESEARCH ON PREMATURE EJACULATION}

So far, three different methods of genetic research on PE have been published.

1. The first method investigates the genetics of the ejaculation time (e.g., the IELT) in men with lifelong PE with IELTs of less than 1 minute [4]. This investigation is based on the hypothesis of Waldinger et al that the skewed distribution of the IELT in the general male population $[17,18]$ in men with lifelong PE $[4,19,41]$ and in any cohort of male Wistar rats [29] is based on genetic factors influencing the central serotonergic system in modulating the duration of the IELT. The methodology of this genetic research consists of real-time, objective stopwatch measurement of the IELT in cohorts of men who actively seek medical treatment for their complaints associated with lifelong PE in terms of lifelong, persistent IELTs of about 1 minute.

2. The second method investigates the genetics of men who complain of $\mathrm{PE}$ in the general male twin population [42-45]. This investigation is based on the view of Jern et al that PE consists of various parameters (such as anteportal ejaculation, number of thrusts, ejaculation latency time, and feelings of control) that are potentially genetically interrelated [42-45]. Their methodology of genetic research consists of sending questionnaires to a large cohort of male homosexual and heterosexual twins irrespective of their wish to seek medical treatment for complaints of PE and without objective stopwatch measurements of the IELT.

3. The third method investigates whether the prevalence of genotypes in men with lifelong PE in terms of an IELT of less than 1 minute differs from the prevalence of these genotypes in the general male population $[46,47]$, without investigating potential associations of genetic polymorphism with the IELT (as used in the first method). This investigation is based on the view that men with lifelong $\mathrm{PE}$ have a different genotype profile than do men without lifelong PE.

\section{DIFFERENCES BETWEEN THE THREE METHODS}

The three methods differ in (i) the investigated population 
(men with lifelong PE versus general male twin population), (ii) tool of measurement (stopwatch versus questionnaire), (iii) design (prospective real-time IELT measurement versus retrospective IELT estimation), and (iv) variables (IELT versus feelings of control, ejaculation prior to intercourse, number of thrusts, and ejaculation latency time).

However, the major difference between the three study designs pertains to the investigated population. Whereas Janssen et al investigated a selected cohort of men with lifelong $\mathrm{PE}$ who ejaculate within about 1 minute and who present as patients actively seeking treatment [4], Jern et al and Santtilla et al investigated a relatively small group of respondents $(40 \%$; $33 \%)$ recruited from a large general male twin population who did not present as patients seeking medical treatment [42-45].

Moreover, in the studies of Jern et al and Santtilla et al, most (98\%) of the male twins ejaculated after 1 minute [4245]. Of 1,290 twins, only 26 (2\%) twins reported an ejaculation time of less than 1 minute [45]. In contrast, in the study of Janssen et al [4], most (92\%) of the men ejaculated within 1 minute, and only $8 \%$ ejaculated between 1 and 2 minutes.

The third method of genetic research on PE is different from the method of Janssen et al [4]. In this method, men with lifelong PE are selected but instead of investigating potential associations of genetic polymorphisms with the IELT, the prevalence of genotypes in these men with lifelong $\mathrm{PE}$ is compared with the prevalence of these genotypes in a control group. This method has been used by Ozbek et al and Luo et al in Turkey and China $[46,47]$. The outcome of these studies points to a different genetic profile in men with lifelong $\mathrm{PE}$ than in men in the general male population, rather than emphasizing an association between ejaculation time and genetic polymorphism. However, such a difference in genotype profile was not found in the Dutch study of men with lifelong PE by Janssen et al [4]. This discrepancy was explained after re-analysis of the data by Ozbek et al [46], which disclosed that these study populations did not meet Hardy-Weinberg equilibrium, indicating laboratory insufficiencies or patient selection bias [48]. Further studies controlled by Hardy-Weinberg equilibrium are needed to elucidate whether men with lifelong $\mathrm{PE}$ indeed have a higher prevalence of certain genotypes than do males in the general male population.

\section{LIMITATIONS OF THE THREE METHODS}

Each of the three methods has its own limitations. For example, non-stopwatch assessment of the IELT in the general male population may give rise to about $30 \%$ over- and under-estimation of the IELT compared with stopwatch assessment [18]. Therefore, it may be assumed that the non-stopwatch methodology of Jern et al [42-44] and Santtilla et al [45] fails to precisely objectify the IELT duration both in men with an IELT of less than 1 minute and in men with longer IELT durations. Notably, any questionnaire method as has been used by Jern et al and Santtilla et al is inadequate to investigate the subtle influences of genetic polymorphisms on the IELT in men with lifelong PE who ejaculate within 1 minute [42-45].

On the other hand, the methodology of Janssen et al is inadequate to provide an answer to the question of how genetic factors relating to ejaculation are distributed in the general male population [4]. In addition, the design and method of the study of Janssen et al do not have the precision needed to study associations between subjective feelings of control and genetic polymorphisms [4]. The small number of participants in stopwatch studies in general does not allow sufficient power to analyze subjective feelings and possible polymorphisms. Such studies would require a huge cohort of patients.

\section{THE NEED FOR STOPWATCH MEASUREMENTS IN GENETICS}

Interestingly, the current different views on how to perform genetic research on $\mathrm{PE}$ are strikingly similar to the different views that existed in the 1990s on how to perform drug treatment research on $\mathrm{PE}$ [49]. Also in that decade, a number of clinicians favored the stopwatch method to precisely assess the IELT, whereas others used questionnaires to measure control, satisfaction, and ejaculation time [49]. However, a final meta-analysis of drug treatments that were mainly performed in the 1990s confirmed that real-time, prospective stopwatch measurement of the IELT is more accurate than retrospective IELT assessments [2]. Similarly, it is my current view that real-time prospective IELT measurement is pivotal for evidencebased genetic research on $\mathrm{PE}$, acknowledging that this requirement may impede large-scale genetic research of the IELT in the general male population.

\section{CONCLUSIONS}

A substantial number of men in the general population have complaints of PE. However, only a minority of these men are affected by the disorder of lifelong PE or acquired PE, both of which are characterized by a very short ejaculation time. Notably, particularly men with the latter PE subtypes most frequently seek medical treatment for their complaints of PE. On the other hand, men with natural variable PE and particularly those with premature-like ejaculatory dysfunction or subjective $\mathrm{PE}$ complain of $\mathrm{PE}$, whereas their ejaculation time is actually not aberrant from the average ejaculation time in the general male population. For genetic research on $\mathrm{PE}$, it is pivotal to take into account the different etiologies and pathogenesis of the four PE subtypes. For example, if it appears that subjective PE is more associated with social anxiety or specific personality traits than is lifelong PE, then genetic factors associated with social anxiety or these personality traits may more frequently be found in men with subjective PE. By not differentiating the $4 \mathrm{PE}$ subtypes in genetic research, the odds will be increased that genetic outcome data (for example, 
a genetic association with personality traits) will incorrectly be generalized to PE subtypes that are not associated with these outcome data. In addition, the odds will be increased that outcome data that have been found in a subtype of PE with a low prevalence (e.g., lifelong PE) are not found in the rest of the investigated cohort and therefore will incorrectly be dismissed. Moreover, the odds that the aforementioned examples may happen is absolutely increased when measurement of the duration of the IELT is not included in the study design or is inadequately assessed, for example, by a questionnaire instead of with a stopwatch.

Currently, three methods are used to perform genetic research on PE. The three methods differ in the investigated population, tool of measurement, study design, and variables of PE. The small number of genetic studies on PE that have so far been published do not yet allow a conclusion as to which of these methods is the most valid. However, as previously mentioned, it is this author's view that prospective stopwatch measurement of the IELT is pivotal for evidence-based genetic research on the IELT in men with lifelong PE and the three other PE subtypes. Moreover, it is emphasized that in finding associations between serotonergic polymorphisms and the IELT duration in men with lifelong PE, the central serotonergic system is mainly involved in the "modulation" of the ejaculation or IELT and not or just minimally in the spinal ejaculation reflex itself. Because this modulation of the IELT is variable among men and may even be absent, serotonergic polymorphisms may only be found in men who respond to SSRI treatment with an ejaculation delay.

\section{Conflicts of Interest}

The authors have nothing to disclose.

\section{REFERENCES}

1. Waldinger MD, Berendsen HH, Blok BF, Olivier B, Holstege G. Premature ejaculation and serotonergic antidepressants-induced delayed ejaculation: the involvement of the serotonergic system. Behav Brain Res 1998;92:111-8.

2. Waldinger MD, Zwinderman AH, Schweitzer DH, Olivier B. Relevance of methodological design for the interpretation of efficacy of drug treatment of premature ejaculation: a systematic review and meta-analysis. Int J Impot Res 2004;16:369-81.

3. Mos J, Van Logten J, Bloetjes K, Olivier B. The effects of idazoxan and 8-OH-DPAT on sexual behaviour and associated ultrasonic vocalizations in the rat. Neurosci Biobehav Rev 1991;15:505-15.

4. Janssen PK, Bakker SC, Rethelyi J, Zwinderman AH, Touw DJ, Olivier B, et al. Serotonin transporter promoter region (5-HTTLPR) polymorphism is associated with the intravaginal ejaculation latency time in Dutch men with lifelong premature ejaculation. J Sex Med 2009;6:276-84.

5. Schapiro B. Premature ejaculation: a review of 1130 cases. J Urol 1943;50:374-9.

6. Waldinger MD, Rietschel M, Nöthen MM, Hengeveld MW, Olivier B. Familial occurrence of primary premature ejaculation. Psychiatric Genetics 1998;8:37-40.

7. Waldinger MD, Schweitzer DH. Changing paradigms from a his- torical DSM-III and DSM-IV view towards an evidence based definition of premature ejaculation. Part II--proposals for DSM-V and ICD-11. J Sex Med 2006;3:693-705.

8. Waldinger MD. Premature ejaculation: definition and drug treatment. Drugs 2007;67:547-68.

9. Laumann EO, Paik A, Rosen RC. Sexual dysfunction in the United States: prevalence and predictors. JAMA 1999;281:53744.

10. Laumann EO, Paik A, Glasser DB, Kang JH, Wang T, Levinson $\mathrm{B}$, et al. A cross-national study of subjective sexual well-being among older women and men: findings from the Global Study of Sexual Attitudes and Behaviors. Arch Sex Behav 2006;35:145-61.

11. Serefoglu EC, Yaman O, Cayan S, Asci R, Orhan I, Usta MF, et al. Prevalence of the complaint of ejaculating prematurely and the four premature ejaculation syndromes: results from the Turkish society of Andrology Sexual Health Survey. J Sex Med 2010;Epub ahead of print

12. Shindel A, Nelson C, Brandes S. Urologist practice patterns in the management of premature ejaculation: a nationwide survey. $\mathrm{J}$ Sex Med 2008;5:199-205.

13. Waldinger MD. The need for a revival of psychoanalytic investigations into premature ejaculation. J Mens Health Gend $2006 ; 3: 390-6$.

14. Waldinger MD, Schweitzer DH. The use of old and recent DSM definitions of premature ejaculation in observational studies: a contribution to the present debate for a new classification of PE in the DSM-V. J Sex Med 2008;5:1079-87.

15. Waldinger MD. Premature ejaculation: state of the art. Urol Clin North Am 2007;34:591-9.

16. Waldinger MD. Premature ejaculation: different pathophysiologies and etiologies determine its treatment. J Sex Marital Ther 2008;34:1-13.

17. Waldinger MD, Quinn P, Dilleen M, Mundayat R, Schweitzer DH, Boolell M. A multi-national population survey of intravaginal ejaculation latency time. J Sex Med 2005;2:492-7.

18. Waldinger MD, McIntosh J, Schweitzer DH. A five-nation survey to assess the distribution of the intravaginal ejaculatory latency time among the general male population. J Sex Med 2009;6:288895.

19. Waldinger MD, Hengeveld MW, Zwinderman AH, Olivier B. An empirical operationalization study of DSM-IV diagnostic criteria for premature ejaculation. Int J Psychiatry Clin Pract 1998;2: 287-93.

20. Serefoglu EC, Cimen HI, Atmaca AF, Balbay MD. The distribution of patients who seek treatment for the complaint of ejaculating prematurely according to the four premature ejaculation syndromes. J Sex Med 2010;7:810-5.

21. Masters WH, Johnson VE. Premature ejaculation. In: Masters WH, Johnson VE, editors. Human sexual inadequacy. Boston: Little, Brown; 1970;92-115.

22. Waldinger MD, Schweitzer DH. Changing paradigms from an historical DSM-III and DSM-IV view toward an evidence-based definition of premature ejaculation. Part I--validity of DSM-IVTR. J Sex Med 2006;3:682-92.

23. Waldinger MD, Schweitzer DH. The DSM-IV-TR is an inadequate diagnostic tool for premature ejaculation. J Sex Med 2007;4:8223.

24. Hellstrom WJ. The DSM-IV-TR is an appropriate diagnostic tool for premature ejaculation. J Sex Med 2007;4:252.

25. McMahon CG, Althof SE, Waldinger MD, Porst H, Dean J, Sharlip ID, et al. An evidence-based definition of lifelong premature ejaculation: report of the International Society for Sexual Medicine 
(ISSM) ad hoc committee for the definition of premature ejaculation. J Sex Med 2008;5:1590-606.

26. Althof SE, Abdo CH, Dean J, Hackett G, McCabe M, McMahon $\mathrm{CG}$, et al. International Society for Sexual Medicine's guidelines for the diagnosis and treatment of premature ejaculation. J Sex Med 2010;7:2947-69.

27. Olivier B, Chan JS, Pattij T, de Jong TR, Oosting RS, Veening JG, et al. Psycho-pharmacology of male rat sexual behavior: modeling human sexual dysfunctions? Int J Impot Res 2006;18(Suppl 1): S14-23.

28. de Jong TR, Veening JG, Waldinger MD, Cools AR, Olivier B. Serotonin and the neurobiology of the ejaculatory threshold. Neurosci Biobehav Rev 2006;30:893-907.

29. Pattij TR, de Jong TR, Uitterdijk A, Waldinger MD, Veening JG, Cools AR, et al. Individual differences in male rat ejaculatory behaviour: searching for models to study ejaculation disorders. Eur J Neurosci 2005;22:724-34.

30. Waldinger MD. Lifelong premature ejaculation: definition, serotonergic neuro-transmission and drug treatment. World J Urol 2005;23:102-8

31. Chan JS, Snoeren EM, Cuppen E, Waldinger MD, Olivier B, Oosting RS. The serotonin transporter plays an important role in male sexual behavior: a study in serotonin transporter knockout rats. J Sex Med 2010;Epub ahead of print

32. Coolen LM, Olivier B, Peters HJ, Veening JG. Demonstration of ejaculation-induced neural activity in the male rat brain using 5-HT1A agonist 8-OH-DPAT. Physiol Behav 1997;62:881-91.

33. Truitt WA, Coolen LM. Identification of a potential ejaculation generator in the spinal cord. Science 2002;297:1566-9.

34. Maxwell L, Maxwell DJ, Neilson M, Kerr R. A confocal microscopic survey of serotoninergic axons in the lumbar spinal cord of the rat: co-localization with glutamate decarboxylase and neuropeptides. Neuroscience 1996;75:471-80.

35. Marson L, McKenna KE. A role for 5-hydroxytryptamine in descending inhibition of spinal sexual reflexes. Exp Brain Res 1992; 88:313-20.

36. Murphy AZ, Hoffman GE. Distribution of gonadal steroid receptor-containing neurons in the preoptic-periaqueductal graybrainstem pathway: a potential circuit for the initation of male sexual behaviour. J Comp Neurol 2001;438:191-212.

37. Kippin TE, Sotiropoulos V, Badih J, Pfaus JG. Opposing roles of the nucleus accumbens and anterior lateral hypothalamic area in the control of sexual behaviour in the male rat. Eur J Neurosci
2004;19:698-704.

38. Lorrain DS, Matuszewich L, Friedman RD, Hull EM. Extracellular serotonin in the lateral hypothalamic area is increased during the postejaculatory interval and impairs copulation in male rats. J Neurosci 1997;17:9361-6.

39. Allard J, Truitt WA, McKenna KE, Coolen LM. Spinal cord control of ejaculation. World J Urol 2005;23:119-26.

40. Waldinger MD. Four measures of investigating ejaculatory performance. J Sex Med 2007;4:520.

41. Waldinger MD, Zwinderman AH, Olivier B, Schweitzer DH. The majority of men with lifelong premature ejaculation prefer daily drug treatment: an observational study in a consecutive group of Dutch men. J Sex Med 2007;4:1028-37.

42. Jern P, Santtilla P, Witting K, Harlaar N, Johansson A, von der Pahlen B, et al. Premature and delayed ejaculation: genetic and environmental effects in a population-based sample of Finnish twins. J Sex Med 2007;4:1739-49.

43. Jern P, Santtilla P, Johansson A, Varjonen M, Witting K, Algars $\mathrm{M}$, et al. Indicators of premature ejaculation and their associations with sexual distress in a population-based sample of young twins and their siblings. J Sex Med 2008;5:2191-201.

44. Jern P, Santtilla P, Johansson A, Varjonen M, Witting K, von der Pahlen B, et al. Subjectively measured ejaculation latency time and its association with different sexual activities while controlling for age and relationship length. J Sex Med 2009;6:2568-78.

45. Santtilla P, Jern P, Westberg L, Walum H, Pedersen CT, Eriksson $\mathrm{E}$, et al. The dopamine transporter gene (DAT1) polymorphism is associated with premature ejaculation. J Sex Med 2010;7: 1538-46.

46. Ozbek E, Tasci AI, Tugcu V, Ilbey YO, Simsek A, Ozcan L, et al. Possible association of the 5-HTTLPR serotonin transporter promoter gene polymorphism with premature ejaculation in a Turkish population. Asian J Androl 2009;11:351-5.

47. Luo S, Lu Y, Wang F, Xie Z, Huang X, Dong Q, et al. Association between polymorphisms in the serotonin $2 \mathrm{C}$ receptor gene and premature ejaculation in Han Chinese subjects. Urol Int 2010;85: 204-8.

48. Waldinger MD, Janssen PK, Schweitzer DH. Hardy Weinberg equilibrium in genetic $\mathrm{PE}$ research remains critical to avoid misinterpretation. Asian J Androl 2009;11:524.

49. Waldinger MD. Towards evidence-based drug treatment research on premature ejaculation: a critical evaluation of methodology. Int J Impot Res 2003;15:309-13. 